\title{
Erratum to: The characteristics of ultraviolet radiation in arid and semi-arid regions of China
}

\author{
Bo Hu • Yue Si Wang • Guang Ren Liu
}

Published online: 21 December 2011

(C) Springer Science+Business Media B.V. 2011

\section{Erratum to: J Atmos Chem (2011) \\ DOI 10.1007/s10874-011-9204-3}

The original version of this article unfortunately contained a mistake. Figure $5 \mathrm{~b}$ was incorrect. The corrected Figure $5 \mathrm{~b}$ is given below

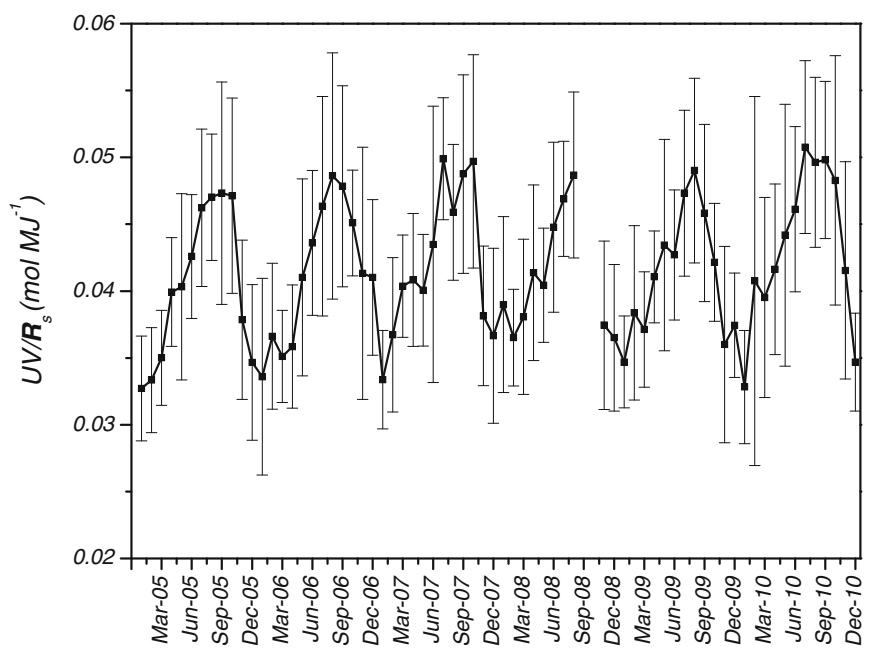

(b) Semi-arid region (represented by Ansai site)

The online version of the original article can be found at http://dx.doi.org/10.1007/s10874-011-9204-3.

B. Hu $(\bowtie) \cdot$ Y. S. Wang $(\bowtie) \cdot$ G. R. Liu

State Key Laboratory of Atmospheric Boundary Layer Physics and Atmospheric Chemistry (LAPC), Institute of Atmospheric Physics, Chinese Academy of Sciences, Beijing, China

e-mail: hb@dq.cern.ac.cn

e-mail: wys@dq.cern.ac.cn 